\title{
Prevalence of Diabetes and Associated Health Risk Factors among Adults in Dubai, United Arab Emirates: Results from Dubai Household Survey 2019
}

\author{
Fatheya Al Awadi ${ }^{a}$ Mohamed Hassanein ${ }^{a}$ Hamid Y. Hussain ${ }^{b}$ \\ Heba Mohammed $^{\mathrm{b}}$ Gamal Ibrahim $^{\mathrm{b}}$ Ahmed Khater $^{\mathrm{b}}$ Eldaw Suliman ${ }^{\mathrm{b}}$ \\ aDiabetes \& Endocrinology Department, Dubai Hospital, Dubai Health Authority, Dubai, UAE; \\ ${ }^{b}$ Data Analysis, Research \& Studies Department, Dubai Health Authority, Dubai, UAE
}

\section{Keywords \\ Prevalence - Diabetes · Adults · Household health survey · \\ Dubai · United Arab Emirates}

\begin{abstract}
Background: The health and social burdens of diabetes mellitus (DM) are steadily increasing worldwide, reflecting the impact of urbanization, industrial transitions, and shifting to nonhealthy, sedentary life patterns', as well as the high sugar, low-fiber food consumptions. All these factors have contributed to the global increase in the prevalence of DM and metabolic disorders. Objectives: The objective is to study the prevalence of DM among adult cohorts in Dubai and the extent of behavioral health risk factors associations. Methodology: A cross-sectional household health survey with multistage, stratified cluster random sample of 9,630 participants including 2,496 households was carried out in Dubai 2019. About 5,371 non-United Arab Emirates (UAE) national, 2,245 UAE-nationals, of different age-groups, gender, education, nationality, smoking, and marital status were included in the survey. The survey questionnaire was adapted from the one used in the World Bank's Living Standards Measurement Surveys (LSMSs) and the WHO's World Health Surveys (WHSs). Self-reported diabetes was considered as well as newly diag-
\end{abstract}

nosed diabetes based on $\mathrm{HbA} 1 \mathrm{C}$ results. About 75 welltrained surveyors, 25 well-trained nurses, and other laboratory technicians conducted the survey. SPSS 21 and Stata 12 software was used for data management. Results: The data indicate that the prevalence of diabetes among Dubai Emiratis is much higher than Dubai expats (19.3 vs. $12.4 \% p=0.000$ ). The association between diabetes and age was evident regardless of nationality. Rates of diabetes were higher in males $(15.4 \%)$ compared to females $(11.8 \%)$ ( $p<0.001)$. About $11.2 \%$ of those considered overweight have DM, while the prevalence is $21.5 \%$ in obese people $(p=0.000)$. Physical inactivity, smoking, and hypertension (HTN) were strongly associated with higher rates of DM. Regardless of nationality, lower levels of education were statistically significantly associated with the prevalence of DM $(p=0.000)$, while single marital status was associated with the lowest rate of DM. Conclusions: Dubai household health survey 2019 indicated that the prevalence of DM among Dubai adults was still high as an overall estimation. Higher rates of diabetes were significantly associated with Emirati nationality, older age-groups, male gender, physical inactivity, high BMI, HTN, smoking, marital status of divorced, separated or divorced as well as low educational level groups.

C 2020 The Author(s)

Published by S. Karger AG, Base karger@karger.com www.karger.com/dde

Karger $\%$

BOPEN ACCESS
(C) 2020 The Author(s)

Published by S. Karger AG, Basel

This article is licensed under the Creative Commons AttributionNonCommercial-NoDerivatives 4.0 International License (CC BYNC-ND) (http://www.karger.com/Services/OpenAccessLicense) Usage and distribution for commercial purposes as well as any distribution of modified material requires written permission.
Fatheya Al Awadi

Head of Unit \& Consultant, Endocrinology Section

Dubai Hospital, Dubai Health Authority

Al Khaleej Street, Al Baraha, Dubai 7272 (UAE)

alawadi1122@hotmail.com 


\section{Introduction}

Diabetes mellitus (DM) is recognized as a global public health problem [1]. The WHO ranked diabetes to be the 7 th leading cause of death in 2016, based on the findings of the global projections of the causes of death [2].

The prevalence of diabetes in the United Arab Emirates (UAE) was reported by the International Diabetes Federation (IDF) to be $16.3 \%$ compared to $9.3 \%$ worldwide [3]. Recent studies in UAE show that the prevalence of DM in Northern Emirates was as high as $25.1 \%$ in UAE-nationals and $19.1 \%$ in expatriates $[4,5]$. However, in emirate of Dubai, the overall prevalence of DM was $15.2 \%$ according to the latest findings of the 2014/17 Dubai Household Survey [6].

Identifying individuals with current undiagnosed diabetes is of crucial importance. Prolonged undiagnosed diabetes can have higher risk of diabetes-related complications, increased healthcare demands, and related costs [7-9]. The recent figures from Dubai Health Survey 2017 revealed that $10.8 \%$ of the population was unaware of their diabetes condition [6].

Various modifiable and nonmodifiable risk factors are associated with diabetes. Risk factors include aging, male gender, genetics, obesity, family history of diabetes, physical inactivity, excessive alcohol ingestion, and tobacco use among others [10-12].

In 2019 according to Dubai Statistics Center (DSC), the total population of Dubai was 3,355,900 of which males make up to $69 \%$ of the total population, and $65 \%$ of the residents aged between 25-49 years [13]. The recent and rapid socioeconomic development of the GCC countries has been associated with rising prevalence of many chronic health problems including diabetes $[14,15]$. This pattern was obvious for Dubai, as the sedentary lifestyle, consumption of fast food and adoption of social smoking habits by its residents infiltrated greatly into the culture [16].

The Dubai Health Authority (DHA) monitors the health status of the population to ensure excellence in healthcare for people living in the emirate. Therefore, it conducts a household survey on a 5-years interval, in collaboration with the (DSC). The survey investigates wide range of health, social, and economic topics as well as testing for undiagnosed diabetes and prediabetes with $\mathrm{HbAlc}$ among the sampled adult population of Dubai. For the sake of feasibility and ease of use, DHHS-2019 used $\mathrm{HbA1c}$ as the screening test for DM [17]. This report focused on data from the DHHS-2019 regarding the prevalence of diabetes (diagnosed and undiagnosed) among the adult population of Dubai.

Prevalence of Diabetes in Dubai

\section{Participants and Methods}

The diabetes data are part of the Dubai household health survey (DHHS), a population-based cross-sectional survey that was conducted in 2019. The survey used a multistage stratified cluster sampling technique as per WHO criteria. It covered different parts of emirate of Dubai (selected clusters in selected geographical areas). Out of the total number of adults aged $18+$ years in the survey participants, 2,245 responded to the diabetes assessment and 1,799 did the blood test (70.2\%) which constituted the sample size for this study. The proportion of UAE-nationals within the sample was over-sampled, and this was corrected by weighting. Each participant was assigned a sampling weight, which was inversely proportional to the probability of selection.

In addition to a personal interview concerning health behaviors (such as smoking, physical activity, and alcohol use), participants underwent selected clinical measurements, including HbA1c percentage test, blood pressure, and anthropometry. HbA1c levels are as follows: $(<5.7 \%)$ considered normal (nondiabetic), between $(5.7$ and $<6.5 \%)$ consider prediabetics, and $(\geq 6.5 \%)$ considered as diabetes as per WHO criteria [18]. Diabetes was further classified into 2 groups, known DM for the self-reported status and newly diagnosed DM for those who were diagnosed during the survey.

BMI values $(<25)$ were considered normal, while values between (25-29.9) were classified as overweight, and BMI values of 30 and above indicated obesity. Physical activity was categorized as active or not, with those reporting more than 150 min of exercise a week being classified as active as per the WHO recommendations. Hypertension (HTN) was defined as a self-report diagnosis and/or blood pressure measurement of ( $\geq 140 / 90 \mathrm{~mm} \mathrm{Hg})$.

The descriptive analytical research methodology tools were used applied carefully to describe the prevalence of diabetes in the emirate of Dubai and to study the relationship between diabetes and other related variables included in the survey data, Social package of statistical sciences software SPSS, V.21 (IBM, Armonk, NY, USA), and Stata 12 (STATA Corp., College Station, TX, USA) were used to obtain the results. $\chi^{2}$ test was applied to compare frequency distributions of 2 variables, and Pearson Correlation test was used to evaluate the power of relationship using the calculated numbers for the population. Statistical significance was set at $(p<$ 0.05).

\section{Results}

The total survey sample included 2,245 adults (18+) years. The main demographic characteristics of the surveyed sample are detailed in Table 1 . Results showed that males represented $47.1 \%$ of the sample. The highest agegroup were those between (30-39) years $(32.3 \%)$, followed by the (40-49) years $21.3 \%$. Over half of the respondents $(55.9 \%)$ have a university degree, and above and $68.5 \%$ are currently married.

The results of DHSS 2019 indicate that the total prevalence of diabetes in Dubai is $13.7 \%$ with $11.5 \%$ known diabetes and $2.1 \%$ newly diagnosed diabetes. The preva-

Dubai Diabetes Endocrinol J 2020;26:164-173 


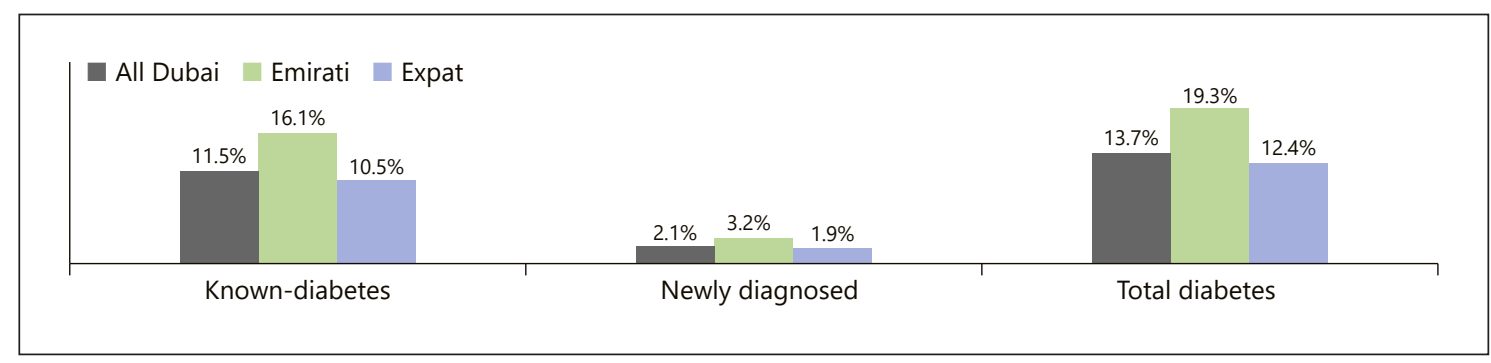

Fig. 1. Total prevalence of DM in Dubai according to nationality, DHHS-2019. DM, diabetes mellitus.

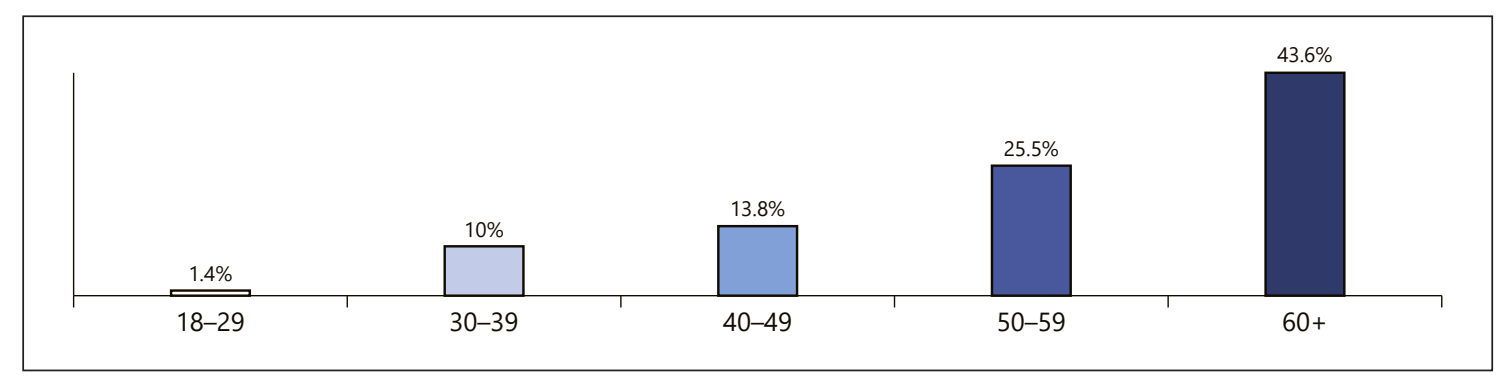

Fig. 2. Total prevalence of DM in all Dubai according to age, DHHS-2019. DM, diabetes mellitus.

lence of diabetes among Dubai Emiratis is much higher than Dubai expats (19.3 vs. 12.4\%). Indeed, all 3 parameters of diabetes (Known, newly diagnosed, and total diabetes) were higher in Dubai Emiratis compared to Dubai expat (Fig. 1).

The data also indicate that the prevalence of diabetes is increasing according to age where those in the agegroup of $18-29$ has $1.4 \%$ diabetes, compared to $43.6 \%$ for those aged $60+$ (Fig. 2). There was statistically highly difference in frequency distribution between age-group and nationality (Pearson correlation $=0.983, p<0.001$ ).

This direct relationship between prevalence of diabetes and age was evident in both Dubai Emiratis and expats. Table 2 includes the results of known diabetics and newly diagnosed DM in relation to age and nationality. These parameters were higher in Dubai Emiratis compared to Dubai expats in all age-groups with the exception of those aged 30-39 years where the prevalence was higher in Dubai expats. All these parameters were statistically significant $\left(\chi^{2}\right.$ test $\left.=4,942, p<0.001\right)$ for known diabetic and newly diagnosed $\left(\chi^{2}\right.$ test $\left.=7,715, p<0.001\right)$.

Furthermore, the prevalence of diabetes is linked to gender as rates of diabetes were higher in males compared to females regardless of nationality (Fig. 3). The results show that $15.4 \%$ of males compared to $11.8 \%$ of females in Dubai have DM ( $\chi^{2}$ test $\left.=5,886, p<0.001\right)$.
Table 1. Main demographic characteristics of the surveyed sample, DHHS-2019

\begin{tabular}{lll}
\hline Parameter & Variables & Total, \% \\
\hline National & Emirati & 52.9 \\
& NonEmirati & 47.1 \\
\hline Gender & Male & 47.1 \\
& Female & 52.9 \\
\hline Age-group & $18-29$ & 17.2 \\
& $30-39$ & 32.3 \\
& $40-49$ & 21.3 \\
& $50-59$ & 10.6 \\
& $60+$ & 18.6 \\
\hline Education & No educations & 8.4 \\
& Primary & 3.5 \\
& Secondary & 32.1 \\
& University + & 55.9 \\
\hline Marital status & Married & 68.5 \\
& Separated/divorced/widow & 11.4 \\
& Single & 20.2 \\
\hline
\end{tabular}

Normal BMI was associated with $7.5 \%$ total prevalence of DM in Dubai, compared to $11.2 \%$ in those considered overweight, and $21.5 \%$ in obese people (Fig. 4). The relation between BMI and DM was statistically significant (Pearson correlation $=0.972, p=0.000)$.

Al Awadi/Hassanein/Hussain/ Mohammed/Ibrahim/Khater/Suliman 


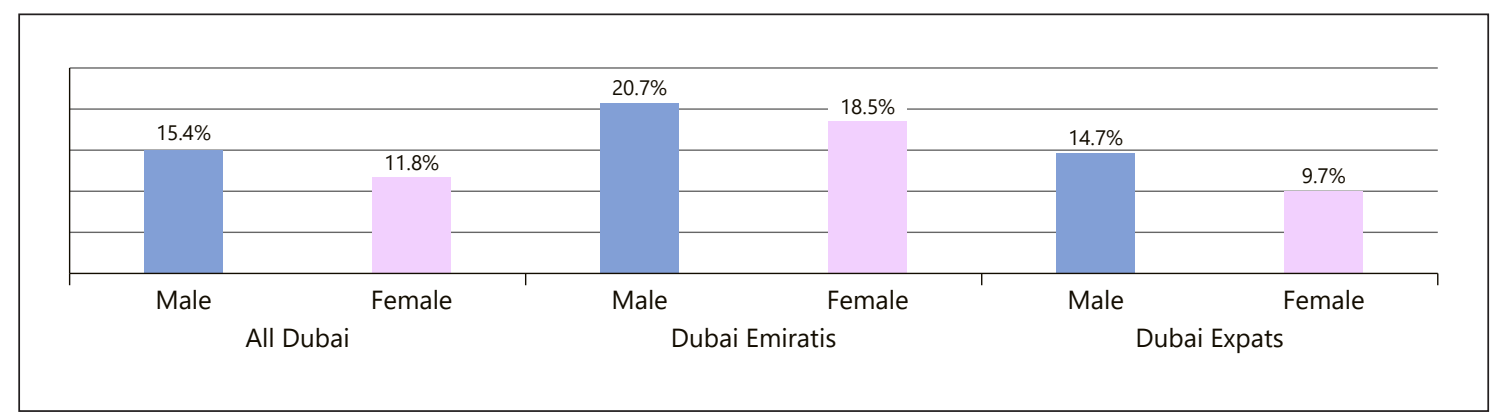

Fig. 3. Total prevalence of DM in Dubai according to gender and nationality, DHHS-2019. DM, diabetes mellitus.

Table 2. Total prevalence of DM in Dubai according to age and nationality, DHHS-2019

\begin{tabular}{lllllll}
\hline \multirow{2}{*}{ Age, years } & \multicolumn{2}{l}{ Known-diabetic } & & \multicolumn{2}{l}{ Newly diagnosed } & \multirow{2}{*}{$p$ value } \\
\cline { 2 - 3 } & Emirati, \% & expat, \% & & Emirati, \% & expat, \% & \\
\hline $18-29$ & 2.90 & 0.80 & & 0.50 & 0.00 & $<0.001$ \\
$30-39$ & 3.60 & 6.50 & & 0.80 & 4.40 & \\
$40-49$ & 20.60 & 11.6 & & 3.50 & 0.30 & \\
$50-59$ & 25.30 & 22.2 & & 7.60 & 1.10 & \\
$60+$ & 56.40 & 35.9 & & 7.90 & 0 & \\
\hline
\end{tabular}

DM, DM, diabetes mellitus.

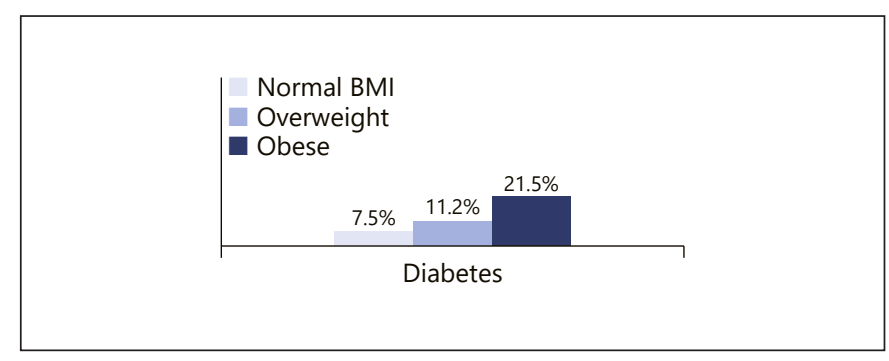

Fig. 4. Total prevalence of DM in Dubai according to BMI, DHHS2019. DM, diabetes mellitus.

Details of prevalence of diabetes according to BMI and nationality are in Table 3 . The results show that the relationship of DM prevalence to BMI is evident for both Dubai Emiratis and expats regardless of whether they are known diabetics or newly diagnosed with DM.

Physically active participants are those reporting (>150) $\mathrm{min} /$ week. Table 4 shows that there was lower level of diabetes in active people regardless of nationality compared to those considered as physically inactive $\left(\chi^{2}\right.$ test $=155, p<0.001)$. This was evident in Dubai Emirati where those who are active have $10.2 \%$ prevalence of DM compared to $20.2 \%$ for those who are inactive.

Prevalence of Diabetes in Dubai
Smoking was associated with higher prevalence of DM in DHHS-2019 (smokers 13\%, nonsmokers 7.9\%). This was particularly evident in Dubai Emiratis where 27.9\% of smokers had DM compared to $14.5 \%$ of nonsmokers. There were no newly diagnosed persons with DM in nonsmokers in Dubai. Details of the relationship of smoking and the prevalence of known DM, newly diagnosed diabetes, and total diabetes according to nationality are listed in Table 5. All these parameters were statistically significant $\left(\chi^{2}\right.$ test $\left.=7.28, p=0.026\right)$.

HTN (BP $\geq 140 / 90$ or those reporting previous diagnosis of HTN) was strongly associated with higher rates of DM in DHSS-2019 ( $\chi^{2}$ test $=287.6, p<0.001$ ). This was particularly evident in Dubai Emiratis compared to expats where in those with HTN; the prevalence of DM was $37.6 \%$ compared to $11 \%$ in those without HTN. In Dubai expats, the prevalence of DM in those with HTN was $9.8 \%$ versus $8.1 \%$ in those without HTN (Fig. 5).

Table 6 includes details of prevalence of known diabetes and newly diagnosed diabetes in Dubai according to HTN and nationality. A similar pattern to total diabetes was seen, where in Dubai Emiratis there were much higher rates of newly diagnosed diabetes in hypertensive individuals compared to normotensives. This was not seen in Dubai hypertensive expatriates. These were also statisti- 
Table 3. Total prevalence of DM and prediabetes in Dubai according to BMI and nationality, DHHS-2019

\begin{tabular}{lrll}
\hline BMI and nationality & $\begin{array}{l}\text { Known } \\
\text { diabetic, } \\
\%\end{array}$ & $\begin{array}{l}\text { Newly } \\
\text { diagnosed, } \\
\%\end{array}$ & $\begin{array}{l}\text { Total } \\
\text { diabetes, } \\
\%\end{array}$ \\
\hline Normal BMI Dubai Emiratis & 6.00 & 0.30 & $\mathbf{6 . 3 0}$ \\
Normal BMI Dubai expats & 7.20 & 0.50 & $\mathbf{7 . 7 0}$ \\
Overweight Dubai Emiratis & 13.80 & 3.00 & $\mathbf{1 6 . 8 0}$ \\
Overweight Dubai expats & 9.90 & 0.60 & $\mathbf{1 0 . 5 0}$ \\
Obese Dubai Emiratis & 19.40 & 4.50 & $\mathbf{2 3 . 9 0}$ \\
Obese Dubai expats & 13.60 & 6.80 & $\mathbf{2 0 . 4 0}$ \\
\hline
\end{tabular}

DM, diabetes mellitus.

Table 5. Total prevalence of DM in Dubai according to smoking status and nationality, DHHS-2019

\begin{tabular}{lclc}
\hline Smoking status & $\begin{array}{l}\text { Known } \\
\text { diabetic, \% }\end{array}$ & $\begin{array}{l}\text { Newly } \\
\text { diagnosed, \% }\end{array}$ & $\begin{array}{l}\text { Total } \\
\text { diabetes, \% }\end{array}$ \\
\hline $\begin{array}{l}\text { All Dubai } \\
\text { Nonsmokers }\end{array}$ & 7.90 & 0.00 & $\mathbf{7 . 9 0}$ \\
Smokers & 10.20 & 2.80 & $\mathbf{1 3 . 0 0}$ \\
\hline $\begin{array}{l}\text { Dubai Emiratis } \\
\text { Nonsmokers }\end{array}$ & 14.50 & 0.00 & $\mathbf{1 4 . 5 0}$ \\
Smokers & 21.70 & 6.20 & $\mathbf{2 7 . 9 0}$ \\
$\begin{array}{l}\text { Dubai expats } \\
\text { Nonsmokers }\end{array}$ & 6.30 & 0.00 & \\
Smokers & 7.80 & 2.00 & $\mathbf{6 . 3 0}$ \\
\hline
\end{tabular}

DM, diabetes mellitus.
Table 4. Total prevalence of DM in Dubai according to physical activity and nationality, DHHS-2019

\begin{tabular}{lclc}
\hline Physical activity & $\begin{array}{l}\text { Known } \\
\text { diabetic, \% }\end{array}$ & $\begin{array}{l}\text { Newly } \\
\text { diagnosed, \% }\end{array}$ & $\begin{array}{l}\text { Total } \\
\text { diabetes, \% }\end{array}$ \\
\hline All Dubai & & & \\
$\begin{array}{l}\text { Not physically active } \\
\text { Physically active }\end{array}$ & 10.70 & 0.60 & $\mathbf{1 1 . 2 0}$ \\
\hline $\begin{array}{l}\text { Dubai Emiratis } \\
\text { Not physically active }\end{array}$ & 15.90 & 1.80 & $\mathbf{8 . 7 0}$ \\
$\begin{array}{l}\text { Physically active } \\
\text { Dubai expats }\end{array}$ & 10.20 & 0.00 & $\mathbf{1 0 . 2 0}$ \\
$\begin{array}{l}\text { Not physically active } \\
\text { Physically active }\end{array}$ & 10.10 & 0.00 & $\mathbf{1 0 . 1 0}$ \\
\hline
\end{tabular}

DM, diabetes mellitus.

Table 6. Total prevalence of DM in Dubai according to BP status and nationality, DHHS-2019

\begin{tabular}{llrll}
\hline Nationality & BP status & $\begin{array}{l}\text { Known } \\
\text { diabetic, \% }\end{array}$ & $\begin{array}{l}\text { Newly } \\
\text { diagnosed, \% }\end{array}$ & $\begin{array}{l}\text { Total } \\
\text { diabetes, \% }\end{array}$ \\
\hline All Dubai & No HTN & 7.50 & 1.20 & 8.70 \\
& HTN & 20.60 & 4.20 & 24.80 \\
\hline Dubai Emirati & No HTN & 9.50 & 1.60 & 11.10 \\
& HTN & 30.90 & 6.70 & 37.60 \\
\hline Dubai expats & No HTN & 7.80 & 2.00 & 9.80 \\
& HTN & 7.10 & 1.10 & 8.20 \\
\hline
\end{tabular}

HTN, hypertension; DM, diabetes mellitus.

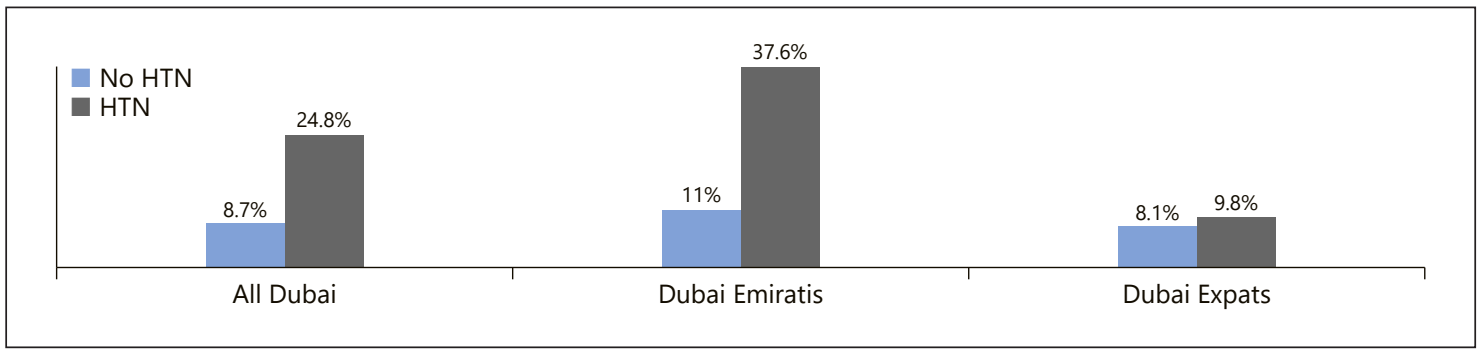

Fig. 5. Total prevalence of DM in Dubai according to HTN and nationality, DHHS-2019. HTN, hypertension; DM, diabetes mellitus.

cally significant $(p<0.001)$, known diabetic $\left(\chi^{2}\right.$ test $=244.7$, $p<0.001)$, and newly diagnosed $\left(\chi^{2}\right.$ test $\left.=35.8, p<0.001\right)$.

Results of DHHS-2019 show that education is strongly associated with prevalence of DM in Dubai regardless of nationality, with known diabetes $\left(\chi^{2}\right.$ test $\left.=238, p<0.001\right)$ and newly diagnosed $\left(\chi^{2}\right.$ test $\left.=5,156, p<0.001\right)$. In all Dubai data, those with no education have $55.1 \%$ prevalence of DM compared to $49.4 \%$ in those with primary education, $17.3 \%$ in those with secondary education, and $10.5 \%$ in those with University degree. Table 7 shows the details 
Table 7. Total prevalence of DM in Dubai according to education and nationality, DHHS-2019

\begin{tabular}{lcll}
\hline Variables & $\begin{array}{l}\text { Known } \\
\text { diabetic, \% }\end{array}$ & $\begin{array}{l}\text { Newly } \\
\text { diagnosed, \% }\end{array}$ & $p$ value \\
\hline All Dubai & & 9.30 \\
No educations & 45.80 & 6.90 \\
Primary & 42.50 & 2.10 \\
Secondary & 15.20 & 1.80 \\
University + & 8.70 & & $<0.001$ \\
\hline Dubai Emiratis & & 11.90 \\
No educations & 52.50 & 6.80 \\
Primary & 39.20 & 1.90 \\
Secondary & 14.00 & \\
University + & 8.40 & 0.00 \\
\hline Dubai expats & & 7.00 \\
No educations & 21.70 & 1.90 \\
Primary & 45.70 & 1.80 \\
Secondary & 16.00 &
\end{tabular}

DM, diabetes mellitus.
Table 8. Total prevalence of DM in Dubai according to marital status and nationality, DHHS-2019

\begin{tabular}{llll}
\hline Variables & Known & $\begin{array}{l}\text { Newly } \\
\text { diagnosed, } \\
\%\end{array}$ & $\begin{array}{l}\text { Total } \\
\%\end{array}$ \\
& & 0 values,
\end{tabular}

\section{All Dubai}

Married

Separated/Divorced/Widow $\quad 27.00 \quad 1.20 \quad \mathbf{2 8 . 2 0}$

Single $\quad 4.10 \quad 0.50 \quad \mathbf{4 . 6 0}$

Dubai Emiratis

$\begin{array}{llll}\text { Married } & 18.60 & 4.40 & \mathbf{2 3 . 0 0}\end{array}$

Separated/Divorced/Widow $\quad 37.00 \quad 2.90 \quad \mathbf{3 9 . 9 0}$

Single $\quad 3.20 \quad 0.40 \quad 3.60$

Dubai expats

$\begin{array}{lrrr}\text { Married } & 11.30 & 2.20 & \mathbf{1 3 . 5 0} \\ \text { Separated/Divorced/Widow } & 19.90 & 0.00 & \mathbf{1 9 . 9 0} \\ \text { Single } & 4.50 & 0.50 & \mathbf{5 . 0 0}\end{array}$

DM, diabetes mellitus.

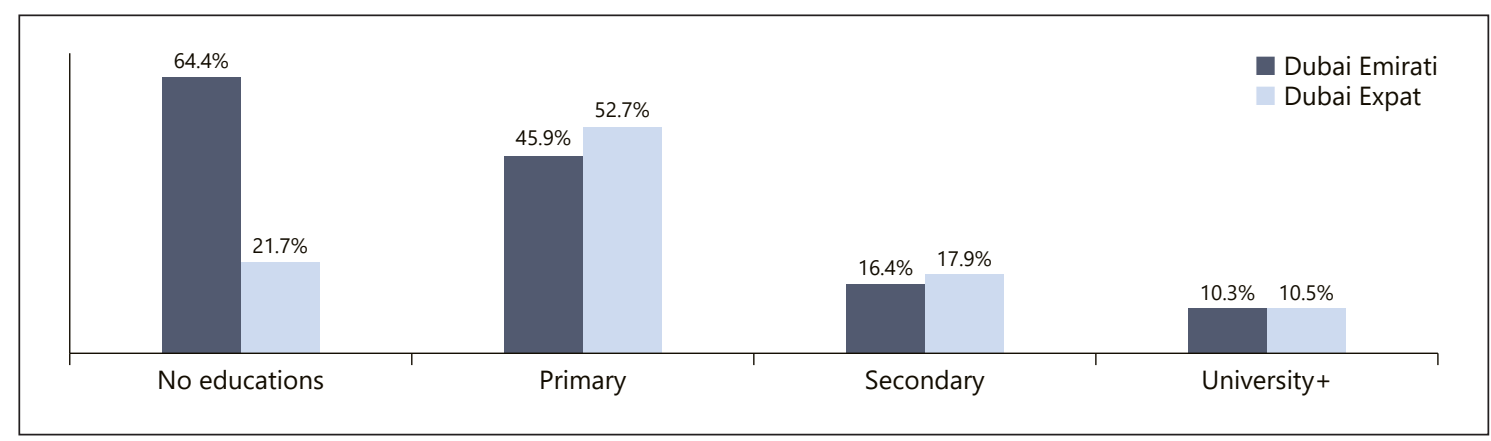

Fig. 6. Total prevalence of DM in Dubai according to education and nationality, DHHS-2019. DM, diabetes mellitus.

of the prevalence in known versus newly diagnosed diabetics according to level of education. The results indicate that there were huge differences in rates of newly diagnosed diabetes among Dubai Emiratis with no education (11.9\%) compared to Dubai expats with no education (0\%).

The differences between prevalence of total diabetes in Dubai Emiratis and expats according to level of education are summarized in Figure 6. This showed that rates of total diabetes were comparable in both groups except for those with no education. These were also statistically significant with $\chi^{2}$ test $=29,640, p<0.001$.

Prevalence of DM appears to be also linked to marital status. Single status was associated with the lowest percentage of DM regardless of previously diagnosed or newly diagnosed and regardless of nationality as detailed in Table 8. The associations were also statistically significant, known diabetic ( $\chi^{2}$ test $=5,132, p<0.001$ ), newly diagnosed $\left(\chi^{2}\right.$ test $\left.=1,077, p<0.001\right)$, and total diabetes $\left(\chi^{2}\right.$ test $\left.=5,782, p<0.001\right)$

\section{Discussion}

The data of the 2019-DHHS are robust as the methodology adopted is similar to that recommended by the WHO, and it included all sectors of Dubai community regardless of nationality. Furthermore, testing for diabetes allowed for analysis of undiagnosed diabetes as well as 


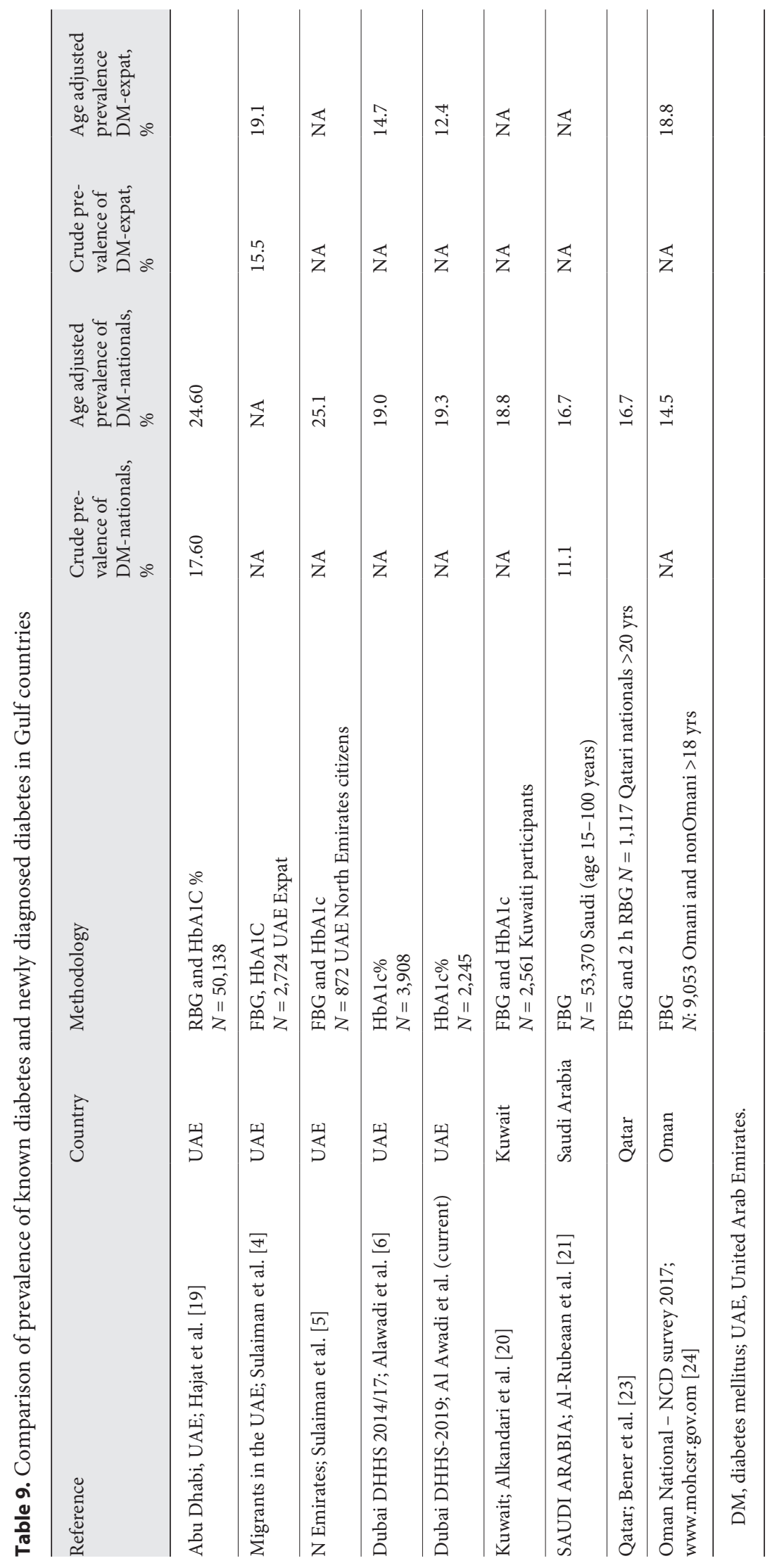




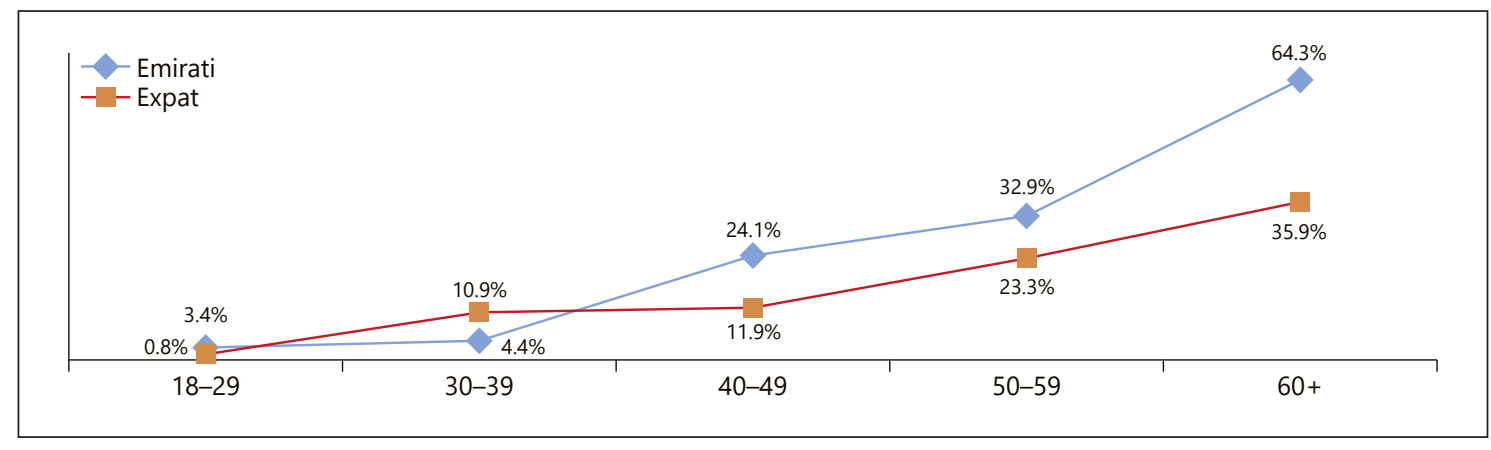

Fig. 7. Correlation of age and prevalence of diabetes in Dubai Emiratis and expats DHHS-2019. DM, diabetes mellitus.

prediabetes, which will be reported upon in a subsequent publication. Many published data in the region focused on prevalence among nationals only; however, the inclusive approach adopted in 2019-DHHS allows for better health information and strategic planning.

The 2019-DHHS opted for $\mathrm{HbAlc} \%$ for diabetes testing despite its relatively higher cost compared to fasting blood glucose to ensure maximum compliance as the survey was undertaken mostly in the evenings. Consequently, this minimized noncompletion of the test. This approach was also adopted in other studies in UAE and Kuwait [4-6, $19,20]$.

The discovery of oil in the GCC countries, over the last 50 years or so, leads to major socioeconomic changes that reflected on the lifestyle of the region. A much more sedentary lifestyle coupled with consumption of westernized type of food contributed to the epidemic of diabetes and obesity in the region [14].

The overall prevalence of diabetes among Emiratis living in Dubai in this survey not only matches the 2014/17 DHHS but also more or less matches the prevalence reported over the last 15 years in UAE or in other Gulf countries. Table 9 includes details of survey conducted in the last 15 years in GCC including details of the size of population tested, their nationality, and the type of test as well as prevalence according to the specified age in the study or the crude prevalence.

The similarities in results between the Kuwait survey and the Dubai data reflect largely the similarities in the survey design [20]. Indeed, the differences seen among the various GCC surveys reflect primarily the differences in methodology or in population tested. For example, as shown in Table 9, several studies used FBG rather than HbAlc. Furthermore, the age of the population included also varied from 15 years onward in Saudi Arabia study to 20+ years in Abu Dhabi and Qatar studies. Overall, the prevalence of diabetes in the region has been very high for the last 2 decades, and action is required to halt this epidemic.

The total prevalence of diabetes in Dubai in this survey is $13.7 \%$, which is lower than the $15.2 \%$ reported in $2014 / 17$ DHHS [6]. Interestingly, the prevalence among Emirati nationals in both surveys is almost identical (19vs. 19.3\%), which reflects the stability of the Dubai Emirati population. However, among expatriates living in Dubai, the prevalence of diabetes in 2019 was $12.4 \%$ compared to $14.7 \%$ in the $2014 / 17$ survey. This change in prevalence in the expatriate population could be related to the much more dynamic changes in this population reflecting employment demands. Malik et al. [22] reported prevalence of diabetes in expatriate population ranging from 12 to $19 \%$ depending on their country of origin. More recently, Suliman et al. [4] reported a rate of $19.1 \%$, and in Oman survey, this was $18.8 \%$, which surprisingly was higher than that reported in Omani nationals [24]. Furthermore, comparison of the 2 recent household health surveys of Dubai shows an increase in diagnosed diabetes and a reduction in newly diagnosed diabetes.

The rate of newly diagnosed diabetes in our study is 13\% of total diabetes, which matches what is reported in USA and Denmark $[25,26]$. The recent heightened knowledge of physicians in Dubai of the magnitude of undiagnosed diabetes could have changed the practice of many physicians for more testing of the at-risk population. Consequently, there was an increase in diagnosed diabetes, which resulted in much lower rates of undiagnosed diabetes. Indeed, this shift of diagnosed diabetes compared to undiagnosed diabetes was also recently reported by Ajlouni et al. [27] in a study in Jordan where they reported rate of diagnosed diabetes of $82.6 \%$ in 2017 compared to $59.6 \%$ in 2009.

The association of increasing age to prevalence of diabetes is well documented in many national, regional, and 
international studies $[4-6,18,19,21-23]$. As shown in Figure 7 the major increment in prevalence of diabetes in Dubai Emiratis among age-group of $40-49$ years as well as $(60+)$ years, while in expatriates living in Dubai it is in the age-group of (30-39) years. Identifying the age-group with the sudden rise is crucial as this could influence active screening cutoff age for the different nationalities.

The interplay of BMI and prevalence of diabetes are almost identical between Emiratis living in Dubai and Expats. In both, the lowest rates of diabetes were noted among those who have normal BMI (Emiratis 6.3\% and Expats 7.7\%) compared to those who are obese (Emiratis 23.9\% and Expats 20.4\%). These data of DHHS comparing BMI to prevalence of diabetes in nationals versus expatriates are of particular importance as there is paucity of regional data in this respect. However, the comparable high prevalence of diabetes regardless of nationality noted in DHHS-2019 is not surprising, as probably the sedentary lifestyle seems to be adopted by the majority in the region leading the wide prevalence of diabetes and obesity leading to many calling to address this combined health problem which is known as diabesity [33].

Most regional studies did not look into the relationship of physical activity and diabetes prevalence. Table 5, of DHHS-2019 indicated that the impact of physical activity on Dubai Emiratis, is clinically highly relevant as physically inactive Emiratis had double the prevalence of those who are active (20.2 vs. $10.2 \%)$. This association was less evident in Dubai expatriates (10.1 vs. 8.3\%). These observations confirm the 2014/17 DHSS data and are a strong indicator that increasing physical activity is of major importance for prevention of diabetes particularly in Emiratis [6]. Indeed, this was also seen in Qatar study where the probability for developing diabetes in those who are physically inactive was very high [23].

Smoking was shown in this survey as well as in many regional and some international studies to be highly associated with prevalence of diabetes $[6,28,29]$. However, in the ADA diabetes risk calculation, smoking is not included as a risk factor [30]. In our survey the prevalence of diabetes was particularly evident in Dubai Emiratis where $27.9 \%$ of smokers had DM compared to $14.5 \%$ of nonsmokers. The association was also seen in Dubai expat but at a lesser extent (9.8 vs. 6.3\%). In Qatar survey, the odds ratio (OR) for prevalence of diabetes was 3.5 in smokers, and this was the highest OR [23]. This relationship between smoking and diabetes prevalence can be explained by the negative effects of smoking ingredients on metabolic physiology.

Several studies showed that HTN was strongly associated with higher rates of DM [4-6, 18, 19, 21-23]. Such finding is always expected as HTN pathophysiological impacts are strongly linked to cardio-metabolic disturbances and eventually leading to vicious cycle of HTN and diabetes.

The current data showed that the rates of diabetes were comparable in both nationals and expats except for those with no education. This indicates that education has better impact on the prevalence of DM in all groups regardless of nationality, and this is clear through modifying lifestyles and adopting healthy behaviors. Similar findings are observed in another Saudi study, which revealed that educational attainment was statistically significant predictors for prediabetes and diabetes [31]. The low level of diabetes in expatriates with no education compared to Dubai nationals probably reflects the fact that this group of expatriates is probably in a physically demanding jobs and is probably of a younger age category, which indirectly reduces their risk of diabetes.

The DHHS-2019 shows that marriage could play protective role against increasing DM prevalence compared to those divorced, widowed, or separated. Similar findings have been identifying in another study, which concluded that married men had lower risk of diabetes [32]. However, being single in 2019-DHHS was associated with the lowest diabetes prevalence. Multiple factors could be contributing to this parameter including the age of the surveyed population.

\section{Summary and Recommendations}

The DHHS-2019 showed a high prevalence of type 2 diabetes in Dubai. Higher rates of diabetes were significantly associated with Emirati nationality, older agegroups, male gender, physical inactivity, high BMI, HTN, smoking, marital status of separated or divorced as well as low educational level groups. These results call for a national household survey to establish if there are any geographical differences in UAE. The data also indicate that collective measures are needed to halt the progress of diabetes in Dubai and also to ensure the best level of service across all sectors of the community for this widely prevalent health issue.

\section{Acknowledgements}

The research team would like to express their appreciation and gratitude to the team of Dubai Statistics Center for their significant contribution to the Household Health Survey. As well as we extend our thanks to Dr. Hussain AlSamt, Pathology and Genetics De-
Al Awadi/Hassanein/Hussain/ Mohammed/Ibrahim/Khater/Suliman 
partment, H.Q., and Ms. Huda BinNatouf from the Pathology Section of PHC, Dubai Health Authority for their significant support throughout the survey.

\section{Statement of Ethics}

Ethical standards have been adhered to in all stages of the research.

\section{Conflict of Interest Statement}

All authors declare that there are no conflicts of interest.

\section{Author Contributions}

All authors contributed to conception of survey the data analysis and manuscript writing.

\section{Study Limitations}

The main limitations of the current study are missing data in some parameters, which limited subgroup analysis. We also did not record family history of diabetes.

\section{References}

1 Al-Lawati J. Diabetes mellitus: a local and global public health emergency! Oman Med J. 2017;32(3):177-9.

2 World Health Organization.

3 International Diabetes Federation. IDF diabetes atlas. 9th ed. Brussels, Belgium: International Diabetes Federation; 2020. p. 7-44.

4 Sulaiman N, Albadawi S, Abusnana S, Mairghani M, Hussein A, Al Awadi F. High prevalence of diabetes among migrants in the United Arab Emirates using a cross-sectional survey. Sci Rep. 2018;8(1):6862.

5 Sulaiman N, Mahmoud I, Hussein A, Elbadawi S, Abusnana S, Zimmet P. Diabetes risk score in the United Arab Emirates: a screening tool for the early detection of type 2 diabetes mellitus. BMJ Open Dib Res Care. 2018;6:e000489.

6 Alawadi F, Hassanein M, Sulaiman E, Hussain HY, Mamdouh H, Ibrahim G, et al. The prevalence of diabetes and prediabetes among population: finding from Dubai household survey 2014. DDE. 2017.

7 Simmons RK, Griffin SJ, Witte DR, BorchJohnsen K, Lauritzen T, Sandbæk A. Effect of population screening for type 2 diabetes and cardiovascular risk factors on mortality rate and cardiovascular events: a controlled trial among 1,912,392 Danish adults. Diabetologia. 2017;60(11):2183-91.

8 Dall TM, Yang W, Halder P, Pang B, Massoudi $\mathrm{M}$, Wintfeld N, et al. The economic burden of elevated blood glucose levels in 2012: diagnosed and undiagnosed diabetes, gestational diabetes mellitus, and prediabetes. Diabetes Care. 2014 Dec;37(12):3172-9.

9 Harris MI. Undiagnosed NIDDM: clinical and public health issues. Diabetes Care. 1993;16(4): $642-52$.

10 Stewart K. Evaluating the effects of a diet and exercise program in people with type 2 diabetes or prediabetes: (the SHAPE3 study). Clin Trial. 2013;4:1-8.

11 Ismail-Beigi F. Pathogenesis and glycemic management of type 2 diabetes mellitus: a physiological approach. Arch Iran Med. 2012; 15(4):239-46.

12 Martins SO, Folasire OF, Irabor AE. Prevalence and predictors of prediabetes among ad- ministrative staff of a tertiary health centre, southwestern Nigeria. Ann Ib Postgrad Med. 2017;15(2):114-23.

13 Dubai Statistics Center. Population by Gender - Emirate of Dubai, 2019. Last accessed. 15.04.2020. Available from: https://www.dsc. gov.ae/en-us/Themes/Pages/Population-andVital-Statistics.aspx? Theme $=42$.

14 Ng SW, Zaghloul S, Ali HI, Harrison G, Popkin $\mathrm{BM}$. The prevalence and trends of overweight, obesity and nutrition-related non-communicable diseases in the Arabian Gulf States. Obes Rev. 2011;12(1):1-13.

15 Saadi H, Carruthers SG, Nagelkerke N, AlMaskari F, Afandi B, Reed R, et al. Prevalence of diabetes mellitus and its complications in a population-based sample in Al Ain, United Arab Emirates. Diabetes Res Clin Pract. 2007; 78(3):369-77.

16 Alawadi F, Abusnana S, Afandi B, Aldahmani $\mathrm{KM}$, Alhajeri O, Aljaberi K, et al. Emirates diabetes society consensus guidelines for the management of type 2 diabetes mellitus. Dubai Diabetes Endocrinol J. 2020.

17 Sacks B. A1C versus glucose testing: a comparison. Diabetes Care. 2011 Feb;34(2):518-23.

18 Silverman RA, Thakker U, Ellman T, Wong I, Smith $\mathrm{K}$, Ito $\mathrm{K}$, et al. Hemoglobin Alc as a screen for previously undiagnosed prediabetes and diabetes in an acute-care setting. Diabetes Care. 2011;34(9):1908-12.

19 Hajat C, Harrison O, Al Siksek Z. Weqaya: a population-wide cardiovascular screening program in Abu Dhabi, United Arab Emirates. Am J Public Health. 2012;102(5):909-14

20 Alkandari A, Longenecker J, Barengo NC, Alkhatib A, Weiderpass E, Al-Wotayan R, et al. The prevalence of pre-diabetes and diabetes in the Kuwaiti adult population in 2014;

21 Al-Rubeaan K, Al-Manaa H, Khoja T, Ahmad $\mathrm{N}$, Al-Sharqawi A, Siddiqui K, et al. The saudi abnormal glucose metabolism and diabetes impact study (SAUDI-DM). Ann Saudi Med. 2014;34(6):465-75.

22 Malik M, Bakir A, Saab BA, Roglic G, King H. Glucose intolerance and associated factors in the multi-ethnic population of the United Arab Emirates: results of a national survey.
Diabetes Res Clin Pract. 2005 Aug;69(2):18895.

23 Bener A, Zirie M, Janahi IM, Al-Hamaq AO, Musallam M, Wareham NJ. Prevalence of diagnosed and undiagnosed diabetes mellitus and its risk factors in a population-based study of Qatar. Diabetes Res Clin Pract. 2009 Apr; 84(1):99-106.

24 Oman National NCD \& their Risk factors survey-2017; Available from: www.mohcsr.gov. om.

25 Selvin E, Wang D, Lee AK, Bergenstal RM, Coresh J. Identifying trends in undiagnosed diabetes in US adults by using a confirmatory definition: a cross-sectional study. Ann Intern Med. 2017;167:769-76.

26 Gl€umer C, Jorgensen T, Borch-Johnsen K.. Prevalence's of diabetes and impaired glucose regulation in a Danish population: the inter99 study. Diabetes Care. 2003;26:2335-40.

27 Ajlouni K, Batieha H, Jaddou Y, Khader N, Abdo M, EI-Khateeb D, et al. Time trends in diabetes mellitus in Jordan between 1994 and 2017. Diabet Med. 2019;36(9):1176-82.

28 Halimi J, Lecomte P, Vol S. Smoking and diabetes, diabetes and metabolism.

29 Saeed A. Association of tobacco products use and diabetes mellitus-results of a national survey among adults in Saudi Arabia. Balkan Med J. 2012 Sep;29(3):247-51.

30 Standards of the medical care in Diabetes-2020 - www.diabetes.org/diabetes care -J anuary 2020-volum 43 supplement 1.

31 Aldossari K, Aldiab A, Jamaan M, Al-Ghamdi SH, Abdelrazik M, Batais MA, et al. Prevalence of prediabetes, diabetes, and its associated risk factors among males in Saudi Arabia: a population-based survey. J Diabetes Res. $2018 \mathrm{Apr}$ 24;2018:2194604

32 Ramezankhani A, Azizi F, Hadaegh F. Associations of marital status with diabetes, hypertension, cardiovascular disease and all-cause mortality: a long term follow-up study. PLoS One. 2019;14(4).

33 Khalil AB, Beshyah SA, Abdella N, Afandi B, Al-Arouj MM, Al-Awadi F, et al. Diabesity in the Arabian Gulf: challenges and opportunities. Oman Med J. 2018 Jul;33(4):273-82. 